\title{
Long-Term Clinical Outcome of Patients Using Risperidone Long-Acting Injectable: The Romanian e-STAR Database
}

\author{
Ioana Micluţia1, Mãdãlina Vrabie ${ }^{1}$, Roxana Ciungu ${ }^{2}$ \\ ${ }^{1}$ Department of Neurosciences, Discipline of Psychiatry, "Iuliu Hatieganu" University of Medicine \& Pharmacy, \\ Emergency County Hospital Cluj, Second Psychiatric Clinic, Cluj-Napoca, Romania \\ ${ }^{2}$ Medical Affairs, Janssen, Division of Johnson \& Johnson Romania, Bucharest, Romania \\ Email: ioanamiclu@yahoo.com, madalina.vrabie@yahoo.com, rciungu@its.jnj.com
}

Received 7 February 2015; accepted 6 March 2015; published 10 March 2015

Copyright @ 2015 by authors and Scientific Research Publishing Inc.

This work is licensed under the Creative Commons Attribution International License (CC BY).

http://creativecommons.org/licenses/by/4.0/

c. (i) Open Access

\section{Abstract}

The objectives of e-STAR Romania (NCT00283517) were to collect clinical outcome data of Romania schizophrenia or schizo-affective disorder patients; prospectively to assess the reasons of treatment initiation, medication usage patterns; to document (long-term) clinical efficacy; and to collect safety data, as well as recording 2-year corresponding retrospective data. In total, 378 eligible subjects were enrolled who were initiated either on risperidone long-acting injectable (RLAI) (290) or on an oral antipsychotic $(\mathrm{OA})(88)$ at baseline as required by the local Summary of the Product Characteristics. Data were collected from per patient both retrospectively and prospectively over a 24-month period at 3-month intervals after starting treatment. The results indicated that subjects suffering from schizophrenia or schizo-affective disorder initiated on RLAI were less likely to be hospitalized within the first 24 months after the initiation of treatment. Moreover, subjects treated with RLAI experienced significant improvements in their illness severity and functioning. Discontinuation rates for RLAI were low and doses were stable throughout the 24 months following the initiation of treatment. In addition, the necessity for supplementary concomitant medication was reduced. Adverse events were reported in $20.3 \%$ (RLAI) and $11.4 \%$ (OA) of the subjects. In general, patients initiated on RLAI and OA at baseline both clinically improved on all assessed parameters but a larger improvement was observed for patients on RLAI. Incidences of reported AEs during the use of RLAI in a naturalistic setting are comparable with those described in clinical studies; however, the incidence of extrapyramidal signs and weight gain was lower than expected.

\section{Keywords}

Schizophrenia Registry, Risperidone Long-Acting Injectable, Hospitalizations, Clinical Outcome, Safety 


\section{Introduction}

There are different opinions regarding the course of schizophrenia: it can be considered a deteriorative disease as the initial observation [1], but it has also been described the pattern of multiple episodes [2], or the currently accepted relapsing course [3] [4]. In some studies even an evolution of progressive amelioration was observed [5]. Based on the few long-term national follow-up studies about one [6] or two decades [7], the majority of schizophrenia patients seem to improve, while only few deteriorate. In order to reconcile opinions and research with real life and multiple interfering factors, the course of schizophrenia is currently accepted as heterogeneous [8] [9].

There is scarce information regarding the real prevalence and evolution of schizophrenia due to few epidemiological studies and long term naturalistic observational studies employ diverse research methods. Some of these facts have been recognized on an international level as barriers against appropriate, prompt diagnosis, and coherent monitoring. With the exception of a few countries [10]-[12], mental health professionals denounce the lack of large cohort studies and national registries for psychiatric disorders, especially for schizophrenia patients. Like in many other countries, the Romanian Ministry of Health does not have a clear overview regarding the epidemiology of schizophrenia patients. There is a gap between the real extent of the disease and the official reported diagnosis because of "masked" diagnoses due to stigma and the under-diagnosis/misdiagnosis, the application for private practice and the "dark zone" of those who never apply for assessment. The utilization of hospital admittance records for research and administrative purposes as indicator of the passive epidemiology for the incidence and prevalence of schizophrenia relies on the assumption that the majority of schizophrenia ill persons will be hospitalized at least once in a life-time as a result of this illness [11]. These data do not reflect accurately the prevalence of schizophrenia in the general population for various reasons; up to $25 \%$ of schizophrenia patients received care only as outpatients [13] and 6.7\% of ambulatory treated patients in a given catchment area had no hospitalizations [14].

The adherence to antipsychotic medication ranges from non-adherence to full adherence, an issue affecting $40 \%-60 \%$ of schizophrenia patients [15]. Poor adherence could be a serious barrier against the achievement of treatment goals as consequences include poor outcome, relapses, re-hospitalizations, and supplementary costs [16]. Non-adherence is currently accepted as intake of less than $80 \%$ of the prescribed medication or gaps of medication of at least seven days [17]. Relapses themselves may imply unpredictable course, less social adjustment, increased time to recover [18], and disturbing psychopathology [19]. Even though adherent patients take over $80 \%$ of the prescriptions, they still have delusions, guilt feelings or somatic concerns [20]. Therefore Acosta et al. [20] consider that many non-adherent patients could be pursued towards adherence, while full adherence should be a goal among adherent patients.

The electronic Schizophrenia Treatment Adherence Registry (e-STAR) is an international, non-interventional, observational study carried out in different countries using a similar design to collect data on clinical (long-term treatment) and economic outcomes in schizophrenia/schizoaffective disorder patients initiated or switched to a new antipsychotic (oral antipsychotics [OA] or risperidone long-acting injectable [RLAI]) in routine clinical practice [21]. An innovative secured web-based system was used to capture 12 months retrospective and 24 months prospective data. As part of the international registry project, e-STAR Romania respected the general design of the naturalistic study but gathered retrospective data for 24 months and did not include the economic analysis.

The objectives of e-STAR Romania were to collect clinical outcome data of Romania schizophrenia/schizoaffective disorder patients, prospectively to assess the reasons of treatment initiation, medication usage patterns and to document clinical efficacy and long-term treatment outcomes (2 years) of patients, as well as collecting 2-year retrospective data regarding hospitalizations and previous treatments.

\section{Methods}

\subsection{Study Design}

The e-STAR study (NCT00283517) was an international, non-interventional, observational survey on the use of RLAI (Rispolept ${ }^{\mathbb{B}}$ Consta $^{\circledR}$ ), with the aim to assess patients' outcomes by existing risk or disease factors, patients characteristics, or previous medication. Study data was collected from 9 October 2008 until 29 June 2011 (first and last observation entered in the database). All patients starting a new antipsychotic medication (RLAI or OA), according to the local Summary of Product Characteristics, were eligible for inclusion in this study. In addition, they had to be ambulatory or not chronically hospitalized (hospitalization at the moment of inclusion not to ex- 
ceed 6 months). Subjects were not eligible if they either (1) participated in another drug-related study at baseline, (2) were chronically hospitalized, (3) suffered from treatment-resistant schizophrenia, or (4) were pregnant or were breastfeeding, or were planning to become pregnant within two years. Patients received the usual treatment and investigations for their condition and were not exposed to experimental treatments or investigations during the study. As this was a non-interventional, observational registry, randomization and blinding were not applicable. The study protocol was reviewed by an independent ethical committee, the National Ethics Committee for Medicines Clinical Studies (Comisia Nationala de Etica pentru Studiul Clinic al Medicamentului, CNESCM). Patients provided their agreement for medical information disclosure in the study after they were informed about all aspects of the study, their voluntary participation and their refusal to be enrolled had no impact on the care that they would receive for the treatment of his/her disease.

When patients consented with the initiation of a new antipsychotic treatment and with the registration of their data in the e-STAR registry, physicians could document the patients' data in the registry. Data were collected from per patient retrospectively over a 24-month period and prospectively over a 24-month period at 3-month $( \pm 2$ weeks) intervals after the initiation of the treatment. The patient's baseline data were collected within the first month following the initiation of the new antipsychotic treatment. The retrospective period started 2 years before baseline and stopped the day before baseline while the prospective (follow-up) period started at baseline and lasted up to 2 years after baseline (baseline included). Following data were collected for the retrospective period: the patient's characteristics, treatment history, hospitalization history (dates, number of days per week) and reasons for initiating the new treatment. In the prospective period, following data were recorded at 3-month intervals: treatment data (antipsychotic medication regimen including adherence and reason for discontinuation, and co-medication), hospitalization data (dates and duration), Clinical Global Impression-Schizophrenia (CGI- S), Global Assessment of Function (GAF), clinical deterioration, safety data.

\subsection{Statistical Methods}

The primary end point was the comparison of the total (cumulative) number of days spent in hospital during and before RLAI. Based on data from a previous study, an overall mean reduction of about 7.0 days was expected (considering data from 2 years with RLAI versus 2 years before RLAI). Therefore, 298 patients were needed in this study to show, with a $90 \%$ power, a significant difference at alpha $=0.05$ using a two-sided paired t-test. Taking into account a drop-out rate of about $20 \%$ during the first year of treatment, a sample of 373 patients starting RLAI treatment was considered to be required. About 124 subjects who started treatment with an OA were to be included as a positive control group in order to be able to control for environmental changes.

Variables were described using descriptive statistics. Comparisons between retrospective and prospective data and between data from subjects who started on RLAI or OA at baseline were made by means of appropriate statistical tests and executed using SAS ${ }^{\circledR}$ version 9.1.3 [SAS Institute, Cary, NC, USA] and were two-sided with a significance level of 0.05. All efficacy results described hereafter represent the "per protocol" population except for the analysis of AEs that was performed on the "all patients" population.

\subsection{Study Population}

Through 36 investigators, 378 subjects were enrolled in this Romanian study: 290 subjects were switched to RLAI as their new antipsychotic treatment at baseline and 88 subjects were switched to an OA at baseline. Of all enrolled subjects, $80.7 \%$ had at least 2 years retrospective data and prospective data. The majority of all enrolled subjects (61.1\%) were outpatients at baseline (178 RLAI subjects and 53 OA subjects).

A slight majority of the enrolled subjects were female (56.9\% [RLAI] and 51.1\% [OA] of subjects). The mean (SD) age at baseline was 38.5 (10.2) and 40.1 (10.1) years, respectively. Approximately two thirds of subjects were diagnosed with schizophrenia (74.5\% [RLAI] and 76.1\% [OA] of subjects), whereas the others (25.5\% and 23.9\%, respectively) suffered from schizoaffective disorder. Diagnosis had been established (mean [SD]) 7.9 (8.2) years (RLAI) and 9.3 (8.3) years (OA) before baseline. No statistically significant differences in baseline patients' characteristics were seen between the 2 treatment groups.

\section{Results}

\subsection{Hospitalization Duration}

Cumulatively over the 24-month period, the mean (SD) total length of hospital stay (see Table 1) had statisti- 
Table 1. Total length of hospital stay per time period in the retrospective and prospective periods (pp population).

\begin{tabular}{|c|c|c|c|c|c|c|c|c|c|}
\hline \multirow{2}{*}{$\begin{array}{l}\text { Mean (SD) } \\
\text { Time } \\
\text { Period }\end{array}$} & \multicolumn{4}{|c|}{ RLAI N = 235} & \multicolumn{4}{|c|}{ OA N = 70} & \multirow{2}{*}{$\begin{array}{c}\text { P-Value } \\
\text { (P-R } \\
\text { Treatment } \\
\text { Difference) }\end{array}$} \\
\hline & $\begin{array}{l}\text { Retrospective } \\
\text { (R) }\end{array}$ & $\begin{array}{l}\text { Prospective } \\
\text { (P) }\end{array}$ & $\mathbf{P}-\mathbf{R}$ & P-Value & $\begin{array}{l}\text { Retrospective } \\
\text { (R) }\end{array}$ & $\begin{array}{l}\text { Prospective } \\
\text { (P) }\end{array}$ & $\mathbf{P}-\mathbf{R}$ & P-Value & \\
\hline 0 - 3 months & $7.4(12.3)$ & $5.8(11.7)$ & $-1.6(15.8)$ & 0.12 & $3.7(8.0)$ & $6.1(9.9)$ & $2.4(12.1)$ & 0.10 & NA \\
\hline 0 - 6 months & 10.5 (18.6) & $7.4(15.0)$ & $-3.1(22.0)$ & 0.032 & $5.0(10.4)$ & $7.1(11.0)$ & $2.1(13.5)$ & 0.19 & NA \\
\hline 0 - 12 months & $15.9(30.5)$ & 9.6 (21.9) & $-6.3(35.5)$ & 0.007 & 7.3 (12.9) & $7.4(11.0)$ & 0.1 (15.9) & 0.95 & 0.0035 \\
\hline 0 - 18 months & $20.0(34.4)$ & $10.8(29.8)$ & $-9.2(43.4)$ & 0.001 & 10.8 (16.9) & $7.6(11.0)$ & $-3.2(18.3)$ & 0.15 & NA \\
\hline 0 - 24 months & $24.1(38.4)$ & 11.5 (32.3) & $-12.6(46.7)$ & $<0.001$ & 14.9 (21.3) & $7.6(11.0)$ & $-7.3(22.5)$ & 0.009 & 0.0886 \\
\hline 3 - 24 months & 16.7 (31.6) & $5.7(29.2)$ & $-11.0(41.0)$ & $<0.001$ & $11.1(19.0)$ & $1.5(5.5)$ & $-9.7(19.2)$ & $<0.001$ & NA \\
\hline
\end{tabular}

cally significantly decreased with 12.6 (46.7) days $(\mathrm{P}<0.001$, RLAI) and with 7.3 (22.5) days $(\mathrm{P}=0.009$, OA). This decrease from 24 months retrospective to 24 months prospective in mean total length of hospital stay was not statistically significantly different between the treatment groups $(P=0.0886)$. The $0-12$ month interval $(\mathrm{Y} 1+)$ was the major contributor to the mean total length of hospital stay in both groups, compared to the next 12 months $(\mathrm{Y} 2+)$ : RLAI 9.6 $(\mathrm{SD}=21.9)$ vs. $1.9(\mathrm{SD}=15.4)$ days and $7.4(\mathrm{SD}=11.0)$ vs. $0.2(1.4)$ days in OA. Taking into account only Y1+ and Y1-, the mean total length of hospital stay after baseline had statistically significantly decreased by $6.3(35.5)$ days compared to before baseline $(\mathrm{P}=0.007)$ in the RLAI group while there was no change in the OA group $(+0.1$ [15.9] days; $\mathrm{P}=0.95)$. This difference in change in the total length of hospital stay was statistically significant in the $0-12$ month time period between the 2 treatment groups $(\mathrm{P}=$ 0.0035). The decrease in total time of the hospital stays was observed in all follow-up time intervals in the RLAI treatment group, except for the 0 - 3 month interval, while for subjects on OA, this could only be observed in the 0 - 24 and 3 - 24 month intervals (see Table 1). For the latter group, the total time spent in hospital was actually higher than before the new treatment within the first year after the start of the new treatment.

\subsection{Number of Hospitalizations}

In the RLAI group, both the number of subjects who required hospitalization at least once per prospective follow-up interval and the number of hospital stays per prospective interval had statistically significantly decreased compared to the corresponding retrospective interval in all follow-up intervals of interest (all $\mathrm{P}<0.001$ ) (see Table 2). Over the entire period of data collection, 92 (39.1\%) subjects had been hospitalized at least once after baseline compared to 160 (68.1\%) subjects before baseline, representing a $42.5 \%$ decrease. The mean (SD) number of hospital stays was 0.54 (0.81) after baseline whereas it was 1.29 (1.27) before baseline.

A similar observation of statistically significantly fewer subjects with hospitalizations or mean number of hospital stays could not be established in subjects who were initiated on OA at baseline, with the exception of the 3 - 24 months interval. Within the first year after the start of the new treatment, the number of subjects in the OA group who required at least one hospitalization per follow-up interval was actually higher than that in the corresponding interval before the new treatment (see Table 2). It should be noted that comparison of the retrospectively gathered hospitalization data indicated that, before baseline, statistically significantly more subjects were hospitalized at least once and hospital stays were more frequent in subjects who started RLAI at baseline than in subjects who were initiated on OA (all $\mathrm{P} \leq 0.0316$ ).

\subsection{Clinical Deterioration, CGI-S and GAF}

Signs of clinical deterioration were not observed in any of the subjects in either group, throughout the 24-month prospective period. At baseline, violent behaviour, suicidal ideation, or self-injury were correspondingly reported by $13.2 \%$ and $12.9 \%, 8.1 \%$ and $10.0 \%$, and $2.1 \%$ and $5.7 \%$ of the subjects on RLAI and OA, respectively, whereas they were not reported in any of the subjects at the 24-month end point. In addition, $50.0 \%$ (RLAI) and $42.9 \%(\mathrm{OA})$ of the subjects had been hospitalized at least once in the 3 months before baseline, whereas $0.4 \%$ and $0 \%$ of the subjects, respectively, were hospitalized at least once in the 3 months before the 24-month time point.

There were no significant differences in baseline CGI-S and GAF scores between the two treatment groups. For all post-baseline assessments, statistically significant (all $\mathrm{P}<0.001$ ) and similar decreases (i.e., improve- 
Table 2. Hospitalizations per time period in the retrospective and prospective periods (pp population).

\begin{tabular}{|c|c|c|c|c|c|c|}
\hline \multirow{2}{*}{$\begin{array}{l}\text { Parameter } \\
\text { Time Period }\end{array}$} & \multicolumn{3}{|c|}{ RLAI N = 235} & \multicolumn{3}{|c|}{ OA N $=70$} \\
\hline & Retrospective & Prospective & P-Value & Retrospective & Prospective & P-Value \\
\hline \multicolumn{7}{|c|}{ Number of subjects with at least one hospitalization per period, n (\%) } \\
\hline 0 - 3 months & $117(49.8)$ & $79(33.6)$ & $<0.001$ & $18(25.7)$ & $28(40.0)$ & 0.064 \\
\hline 0 - 6 months & $127(54.0)$ & $84(35.7)$ & $<0.001$ & $20(28.6)$ & $29(41.4)$ & 0.093 \\
\hline 0 - 12 months & $140(59.6)$ & $90(38.3)$ & $<0.001$ & $26(37.1)$ & $30(42.9)$ & 0.56 \\
\hline 0 - 18 months & $150(63.8)$ & $91(38.7)$ & $<0.001$ & $32(45.7)$ & $31(44.3)$ & 1.00 \\
\hline 0 - 24 months & $160(68.1)$ & $92(39.1)$ & $<0.001$ & $39(55.7)$ & $31(44.3)$ & 0.17 \\
\hline 3 - 24 months & $107(45.5)$ & $30(12.8)$ & $<0.001$ & $29(41.4)$ & $6(8.6)$ & $<0.001$ \\
\hline \multicolumn{7}{|c|}{ Number of hospital stays per period, mean (SD) } \\
\hline 0 - 3 months & $0.56(0.61)$ & $0.38(0.57)$ & $<0.001$ & $0.31(0.65)$ & $0.40(0.49)$ & 0.20 \\
\hline 0 - 6 months & $0.68(0.74)$ & $0.43(0.65)$ & $<0.001$ & $0.39(0.79)$ & $0.44(0.56)$ & 0.32 \\
\hline 0 - 12 months & $0.90(0.97)$ & $0.49(0.74)$ & $<0.001$ & $0.54(0.88)$ & $0.46(0.56)$ & 0.55 \\
\hline 0 - 18 months & $1.12(1.16)$ & $0.51(0.76)$ & $<0.001$ & $0.77(1.21)$ & $0.47(0.56)$ & 0.031 \\
\hline $0-24$ months & 1.29 (1.27) & $0.54(0.81)$ & $<0.001$ & $1.00(1.32)$ & $0.47(0.56)$ & $<0.001$ \\
\hline 3 - 24 months & $0.78(1.08)$ & $0.19(0.55)$ & $<0.001$ & $0.71(1.11)$ & $0.10(0.35)$ & $<0.001$ \\
\hline
\end{tabular}

ments) in CGI-S and GAF score over time were seen in both treatment groups (see Figure 1 and Figure 2).

The majority of subjects were moderately or markedly ill at baseline (72.5\% [RLAI] and 73.9\% [OA]). Mean (SD) CGI-S scores at baseline were 4.63 (0.93) (RLAI) and 4.61 (0.97) (OA). At 24 months after baseline, $72.5 \%$ (RLAI) and 69.6\% (OA) of the subjects were at most mildly ill. None of the subjects on RLAI and $2.9 \%$ of the subjects on OA were severely or extremely severely ill. Mean (SD) CGI-S score gradually decreased over time to 3.00 (0.88) (RLAI) and 3.10 (0.94) (OA) at 24 months after baseline. Analysis of covariance modeling with baseline CGI-S score as covariate provided insight that improvement was greater with higher CGI-S score at baseline $(\mathrm{P}<0.0001)$. Improvements in mean CGI-S scores at the 24 -month end point were larger in inpatients compared to outpatients but it should also be noticed that the CGI-S scores at baseline were higher in inpatients compared to outpatients.

Mean (SD) GAF scores at baseline were 51.0 (14.1) (RLAI) and 51.2 (14.5) (OA) and they gradually increased over time to 74.2 (12.6) (RLAI) and 73.1 (14.1) (OA) at 24 months after baseline. ANCOVA modeling with baseline GAF score as covariate indicated that the improvement was greater with lower GAF scores at baseline $(\mathrm{P}<0.0001)$. GAF scores at baseline were lower in inpatients compared to outpatients but improvements were larger in inpatients compared to outpatients.

\subsection{Initiated Treatment at Baseline}

Subjects were most often switched to RLAI and OA at baseline for reasons of insufficient response to (50.2\% and 58.6\%, respectively) or compliance issues with their previous antipsychotic treatment (26.8\% and $14.3 \%)$.

The majority of subjects (80.4\%) who started RLAI at baseline were still on their treatment at 24 months from baseline. In subjects who were initiated on OA, 67.1\% were continuing their oral therapy at 24 months. Mean (SD) time to discontinuation was 284.9 (186.7) days (RLAI) and 142.7 (143.0) days (OA). The most frequently reported primary reasons for discontinuation within 24 months after baseline were patient/family choice (37.0\% [RLAI]), insufficient response (32.6\% [RLAI] and 39.1\% [OA]), and compliance (13.0\% [both RLAI and OA]).

Comparable percentages of subjects started RLAI at baseline at a dose of $25 \mathrm{mg}$ (46.8\%) or $37.5 \mathrm{mg}$ (45.5\%) while $7.7 \%$ of subjects started RLAI at $50 \mathrm{mg}$. The dose of RLAI remained unchanged throughout the 24 months prospective period in the majority (56.2\%) of subjects. Dose changes occurred at most 3 times: one dose change (33.2\%), 2 dose changes (8.1\%) and 3 dose changes (2.6\%) during the prospective period. The greater part of dose changes were single increases from $37.5 \mathrm{mg}$ to $50 \mathrm{mg}$ (18.7\%) or from $25 \mathrm{mg}$ to $37.5 \mathrm{mg}(9.4 \%)$.

The OA started at baseline was an atypical OA in all (97.1\%), except in 2 subjects. It was most often quetiapinum (30.0\%), olanzapinum (18.6\%), amisulpridum (18.6\%), or aripiprazolum (12.9\%). 

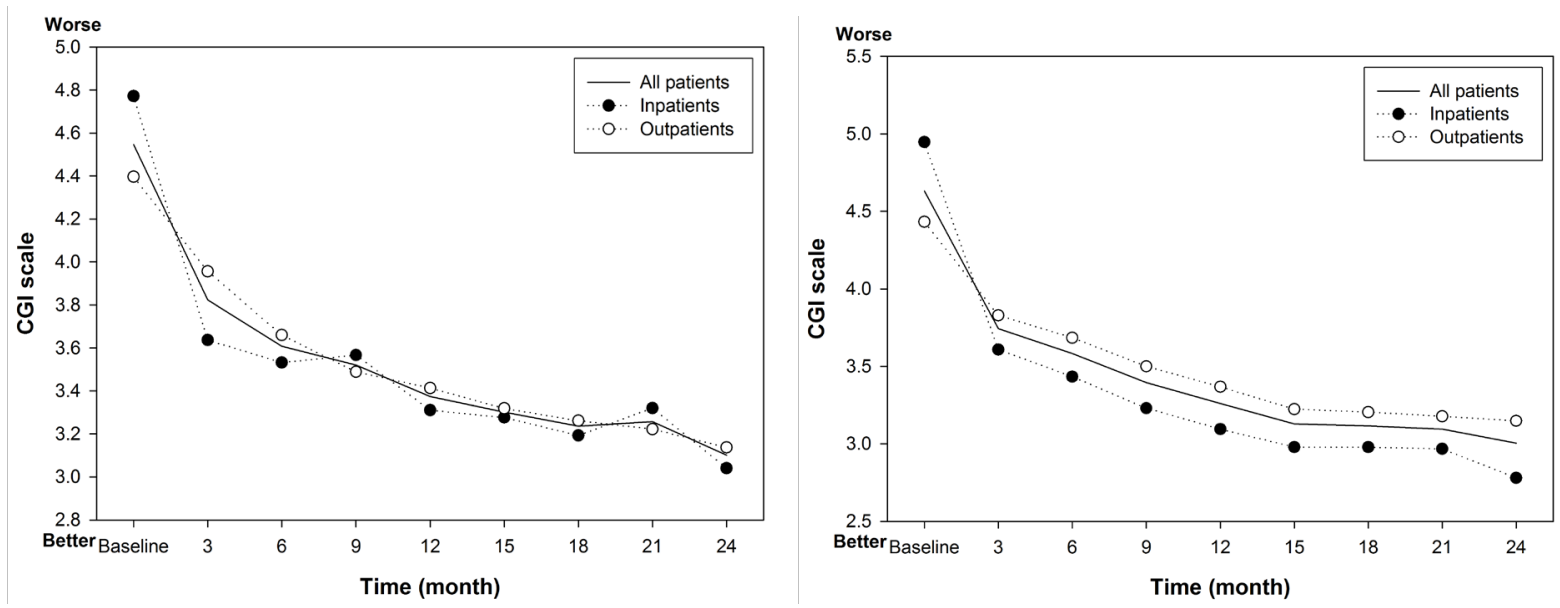

Figure 1. CGI-S score over time in subjects on RLAI (left) and OA (right) at baseline.
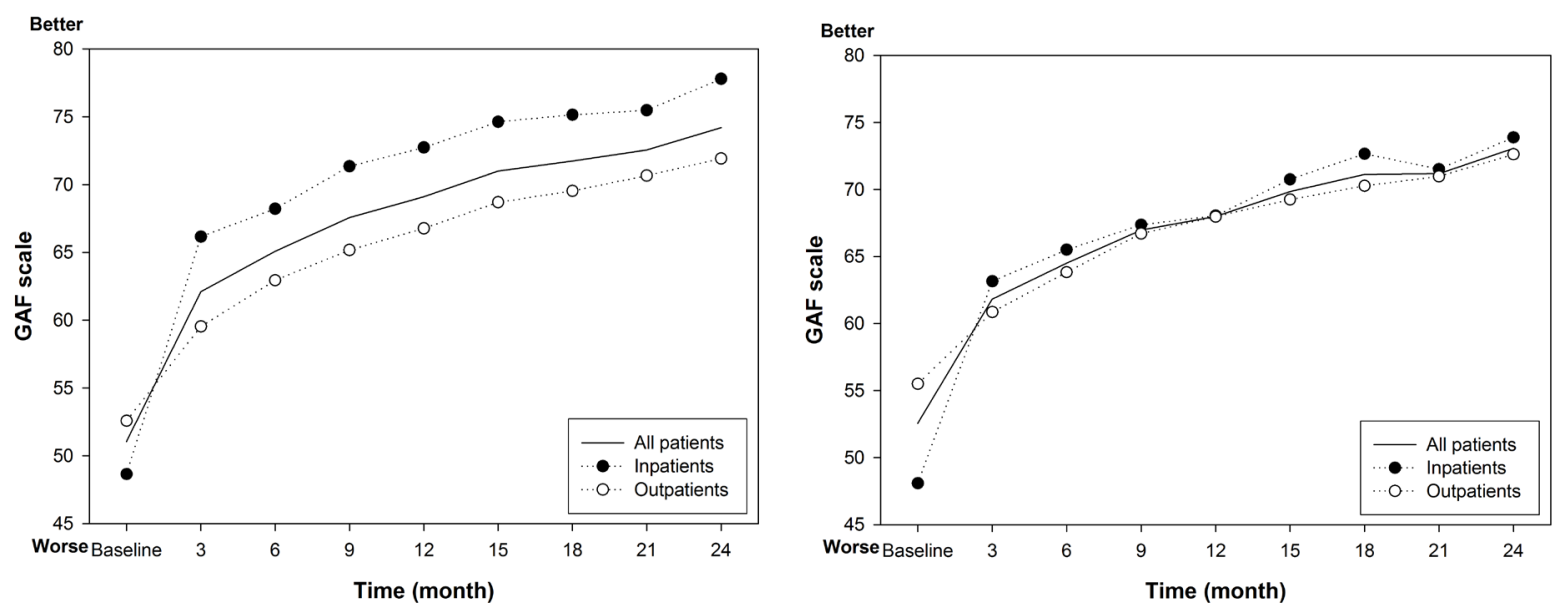

Figure 2. GAF score over time in subjects on RLAI (left) and OA (right) at baseline.

\subsection{Treatment Profile over Time}

The mean (SD) number of antipsychotics used at baseline was 1.9 (0.5) (RLAI) and 1.2 (0.5) (OA). In the RLAI treatment group, RLAI was combined with one atypical OA in $70.2 \%$ of the subjects (of which oral risperidone in $63.0 \%$ ), was given solo in $17.4 \%$ of the subjects and was combined with an atypical and conventional OA in $6.8 \%$ of the subjects at baseline.

Within the first month after baseline, a decrease in the mean number of antipsychotic medications used was recorded in subjects who were initiated on RLAI: from the 1.9 per-subject to approximately 1.0 per subject at 24 months in the prospective period. A shift in antipsychotic use throughout the prospective period to predominantly RLAI monotherapy was observed: $78.3 \%$ of the subjects who started RLAI at baseline were using only RLAI 24 months later.

Of the subjects who started on OA at baseline, the majority (80.0\%) used one atypical OA, 8.6\% combined two atypical OA, and 7.1\% combined an atypical with a conventional OA. Throughout the prospective period, a change in this profile of antipsychotic use was perceived towards $52.9 \%$ of the subjects using no supplementary antipsychotic whereas $40.0 \%$ of the subjects were still on one extra atypical OA at 24 months after baseline. The mean number of antipsychotic medication was approximately 1.1 per subject throughout the prospective period but with a steep drop in the curve to 0.55 per subject at 24 months in the prospective period.

In subjects who started RLAI, $44.3 \%$ were concomitantly on a benzodiazepine, $34.3 \%$ on a mood stabilizer, $16.4 \%$ on an anticholinergic, $10.0 \%$ on a somatic medication, and $9.3 \%$ on an antidepressant at baseline. At 24 months after baseline, statistically significantly fewer subjects were concomitantly using a benzodiazepine, an- 
ticholinergic, or somatic medication, compared to baseline (24.3\%, $6.4 \%$, and $2.9 \%$, respectively) and statistically significantly more subjects were not using any concomitant psychiatric medication (51.4\%) (all $\mathrm{p} \leq 0.016$ ).

In subjects who started on OA at baseline, $42.9 \%$ of the subjects were using a mood stabilizer and $36.7 \%$ were on a benzodiazepine. Anticholinergics, somatic medication, or antidepressants were each used concomitantly in $10.2 \%$ of the subjects. From baseline to 24 months after baseline, the concomitant use of a benzodiazepine decreases significantly to $10.2 \%(\mathrm{P}=0.004)$ and the percentage of subjects who did not use any concomitant psychiatric medication increased significantly to $61.2 \%$ (all $\mathrm{P}<0.001$ ).

There were no statistically significant differences in concomitant psychiatric medication use between the two treatment groups at baseline or at the 24 months after baseline time point, except for a statistically significant difference in benzodiazepine use at 24 months after baseline $(\mathrm{P}=0.0449)$.

\subsection{Safety Results}

In the 290 subjects enrolled in the study and initiated on RLAI at baseline, 91 AEs were reported in 59 (20.3\%) subjects (see Table 3). The majority of these AEs were events coded as psychiatric disorders (14.8\%). By preferred term, the most frequently reported AEs were schizophrenia exacerbation (5.2\%), hospitalization (3.4\%), insomnia (2.8\%), and psychotic features (2.4\%).

In the 88 subjects enrolled in the study and initiated on OA at baseline, 15 AEs were reported in 10 (11.4\%) subjects (see Table 3). As in the group of subjects who were initiated on RLAI at baseline, the majority of AEs were events coded as psychiatric disorders (6.8\%). By preferred term, none of the events were reported in more than one $(1.1 \%)$ subject.

Fifty serious AEs were reported in 36 (12.4\%) of the subjects initiated on RLAI. Apart from the AE hospitalization, the most frequently reported SAEs were schizophrenia exacerbation (4.5\%), psychotic disorder (1.0\%), and psychomotor hyperactivity, depression, and suicidal ideation (0.7\%). In the subjects initiated on OA, 4 SAEs were reported in $4.5 \%$ of the subjects.

\section{Table 3. Adverse events and serious adverse events reported in more than 1 subject.}

\begin{tabular}{|c|c|c|c|c|}
\hline \multirow[b]{2}{*}{$\begin{array}{l}\text { System Organ Class } \\
\text { Preferred Term, n (\%) }\end{array}$} & \multicolumn{2}{|c|}{ AEs } & \multicolumn{2}{|c|}{ SAEs } \\
\hline & $\begin{array}{c}\text { RLAI } \\
\mathbf{N}=\mathbf{2 9 0}\end{array}$ & $\begin{array}{c}\text { OA } \\
\mathrm{N}=\mathbf{8 8}\end{array}$ & $\begin{array}{c}\text { RLAI } \\
\mathbf{N}=\mathbf{2 9 0}\end{array}$ & $\begin{array}{c}\text { OA } \\
\mathrm{N}=\mathbf{8 8}\end{array}$ \\
\hline Subjects with at least one AE & $59(20.3)$ & $10(11.4)$ & 36 (12.4) & $4(4.5)$ \\
\hline Investigations & $4(1.4)$ & $\mathbf{0}$ & $\mathbf{0}$ & $\mathbf{0}$ \\
\hline Weight increased & $3(1.0)$ & 0 & 0 & 0 \\
\hline Metabolism and nutrition disorders & $1(0.3)$ & $2(2.3)$ & $\mathbf{0}$ & $\mathbf{0}$ \\
\hline Nervous system disorders & $8(2.8)$ & $1(1.1)$ & $3(1.0)$ & $\mathbf{0}$ \\
\hline Extrapyramidal disorder & $2(0.7)$ & 0 & 0 & 0 \\
\hline Psychomotor hyperactivity & $2(0.7)$ & 0 & $2(0.7)$ & 0 \\
\hline Psychiatric disorders & $43(14.8)$ & $6(6.8)$ & $26(9.0)$ & $3(3.4)$ \\
\hline Depression & $5(1.7)$ & 0 & $2(0.7)$ & 0 \\
\hline Insomnia & $8(2.8)$ & $1(1.1)$ & 0 & 0 \\
\hline Psychotic disorder & $7(2.4)$ & $1(1.1)$ & $3(1.0)$ & $1(1.1)$ \\
\hline Restlessness & $2(0.7)$ & 0 & $1(0.3)$ & 0 \\
\hline Schizophrenia & $15(5.2)$ & $1(1.1)$ & $13(4.5)$ & 0 \\
\hline Suicidal ideation & $2(0.7)$ & 0 & $2(0.7)$ & 0 \\
\hline Reproductive system and breast disorders & $5(1.7)$ & $1(1.1)$ & $\mathbf{0}$ & $\mathbf{0}$ \\
\hline Amenorrhoea & $3(1.0)$ & $1(1.1)$ & 0 & 0 \\
\hline Surgical and medical procedures & $10(3.4)$ & $1(1.1)$ & $10(3.4)$ & $1(1.1)$ \\
\hline Hospitalization & $10(3.4)$ & $1(1.1)$ & $10(3.4)$ & $1(1.1)$ \\
\hline
\end{tabular}

$\mathrm{N}=$ total number of subjects, $\mathrm{n}=$ number of subjects with that observation. 


\section{Discussion}

\subsection{Group Selection and Demographic Data}

The Romanian patients sample was smaller than that enrolled in some similar studies [21]-[23], baseline demographics such as age and diagnosis proportions being comparable. However, the following differences have to be noticed: female patients exceeded male patients, and a shorter duration of the diagnosis of 7.9 years in RLAI, respectively 9.3 years in the OA group, compared with other international sites that recorded longer durations since the disease elapsed [22] [24]. There was a high rate of "not working" patients in both groups (over 61\%), but it was not specified if those relatively young patients were unemployed, beneficiated of sick leave or welfare. Data from Eastern European countries confirm the tendency to assimilate quit young unemployed schizophrenia patients on sick leave or welfare in a proportion of 31.7\% [25] up to 37.1\% [26]. If summing unemployed Eastern European subjects from the W-SOHO study [26], figures reach 62.4\%, comparable with the current study.

\subsection{Hospitalizations}

The priority of e-STAR has been stated as the description of the "hospitalization patterns", defined as percent of hospitalized patients, number and days of hospitalization per patient compared over equal periods prior and post initiation of the new antipsychotic and expressed as the change in each item between retrospective and prospective period [21]. Regarding the 24 months retrospective data concerning the hospitalization history, the mean cumulative lengths of hospitalizations in subjects initiated further on RLAI decreased significantly with 12.6 ( $\mathrm{SD}=46.7)$ days $(\mathrm{P}<0.001)$. A similar pattern has been noticed in the group of patients switched to another OA: $(-7.3$ [SD $=22.5$ ] days, $\mathrm{P}=0.009)$. The comparison of hospitalization trend between treatment groups during the observation period has not been statistically significant $(\mathrm{P}=0.0886)$. The 24 -month retrospective data suggests that subjects who were initiated on RLAI at baseline were more severely ill than were subjects who were switched to OA in terms of hospitalization needs as the mean total length of hospital stay in the retrospective period in subjects who were on RLAI at baseline was statistically significantly longer than that in subjects who started OA (24.1 [38.4] days versus 14.9 [21.3] days; $\mathrm{P}=0.0374)$.

Although the retrospective design of the current study rendered difficult any powerful comparison to the other country samples participant in the e-STAR study, RLAI patients recorded significantly higher frequencies of hospitalizations than the OA group, as percent of admitted patients, number and duration of hospital stays, but not mean duration of stay [21]. Other country specifics in the 12 months retrospective hospitalization histories were outlined by Rosillon et al. [22] for Germany, Spain and Australia as follows: 58.2 (SD 90.3), 38.3 (SD 51.1), and 66.9 (SD 90.3) days. For the prospective period, the substantial gains in hospitalization decrease were obvious after the first 12 months of treatment with RLAI (13.7\% (prospective period) vs. $35.1 \%$ (retrospective period)), with a mean number of hospitalizations/patient of $0.21 \mathrm{vs.} 0.49$ and a length of stays $3.98 \mathrm{vs.21.21} \mathrm{(P<}$ 0.0001), a trend that continued into the second year of treatment. A decrease of all indicators of the hospitalization patterns was recorded in the OA group during the prospective analysis, but less intense than in RLAI [21].

\subsection{Deterioration, Clinical Impression and Functioning}

Regular assessments were performed at three months bases for the prospective follow-up time span of 24 months, inquiring various areas. Among these, there were no signs of clinical deterioration in any of the subjects in either treatment group, expressed as hospitalization, suicidal ideation, violent behaviour and self-injury. Only few studies are dedicated to long term treatment outcomes, partly due to technical barriers, to the heterogeneity of the disease itself [27], to different research designs. As predictors of deteriorative trajectory might be interpreted with caution because many confounders could interfere, and the influence of treatment on psychopathological course is yet poorly controlled due to medication changes and treatment discontinuation [28]. One third of schizophrenia patients commit suicide attempts and suicide deaths are recorded in $5 \%$ of them. Suicidal risk is being increased early after the onset of the disorder [29], the current study only referred to suicidal ideation, self-harm and violence as deteriorative parameters. A special clarification should be mentioned regarding violent behaviour, which is often wrongly associated as a characteristic of schizophrenia patients, who are rather more at risk to be victims of violence [29]. Exhibited verbal or physical hostility or aggression is lower in Central and Eastern European schizophrenia patients [26].

Clinical severity, judged upon baseline CGI-S scores labeled the majority of patients as "moderate" and 
“marked” ill, with no statistical differences within group comparison, while Olivares et al., 2009 [21] enrolled at baseline more severe patients in the RLAI treatment arm.

Mean CGI-S scores gradually decreased over time, reaching changes at the end of the 24 months of 1.63 (SD $=1.25)$ in the RLAI group, and $1.51(\mathrm{SD}=1.23)$ in the OA group. Statistically significant improvements in CGI-S scores in both treatment groups have been noticed at the end of the prospective follow-up towards "mildly" or "moderately" ill, evolution that had been already endorsed by the similar studies [21].

Analysis of covariance (ANCOVA) modeling with baseline CGI-S score as covariate provided the insight that improvement has been more robust if CGI-S scores were higher at baseline $(\mathrm{P}<0.0001)$. Furthermore, as expected, enrolled severe inpatients better improved than outpatients. It may be assumed that besides the efficacy of antipsychotics, treatment response may also be influenced by a more careful administration regime of antipsychotics to inpatients. General improvements, assessed mainly by CGI-S, GAF and lack of clinical deterioration could be rendered more obviously in these severely ill inpatients.

If symptomatic remission is important both for the affected person as well as for the social network, being a realistic treatment goal, functional remission implies a further step towards recovery [30]. Hence, assessing adequately functionality is still controversial. So far, GAF scale measures satisfactory the subjects’ psychological, social and occupational functioning. Baseline GAF scores outlined similar functioning in both treatment groups, with statistically improvements in functioning from the first post baseline assessment point onwards to the endpoint, with a larger improvement in inpatients. Results are comparable with similar studies at baseline [21] [31]. Results are obvious in favour of RLAI with a 16\% greater improvement in GAF scores over the course of the study [21].

\subsection{Treatment at Baseline and Over Time}

Treatment with RLAI and OA was initiated mainly for the similar reasons compared to other studies, namely lack of efficacy of the previous medication and compliance issues [21] or tolerability problems [23] but in different proportions or order [21] [23], with the recognition of some national specificities [31].

Comparable data could be noticed in the current study regarding the retention rates in the two groups, but a more sophisticated analysis has been performed by Olivares et al. [21], outlining the relation between retentions rates and GAF, age, self-injury and no relation to the previous antipsychotic.

While the Romanian e-STAR study employed equally the $25 \mathrm{mg}$ or 37, $5 \mathrm{mg}$ twice monthly as starting dose, and very seldom the $50 \mathrm{mg}$ RLAI, with a stability throughout the prospective period, with maximum three dose changes (most of the subjects had two dosage changes during the study), other studies recorded a more homogenous distribution of the three starting dosages, and an increase of the dosages during the prospective follow-up [21]. Even though RLAI registered more than a decade of clinical usage, the optimal dosage and frequency of administration regime are still debated [32]. LAI are still mainly recommended for outpatients and during the maintenance phase [33] [34] and dosage increases may be explained by the fact that antipsychotic drugs might lose their effectiveness with time [35].

The usual recommended supplementation of RLAI with oral risperidone within the first weeks after initiation was generally respected by the protocol, represented by the mean of $1.9(\mathrm{SD}=0.5)$ number of antipsychotics. If $70.2 \%$ of RLAI initiated patients were given an OA, other unusual combinations were prescribed for the rest. A shift in antipsychotic use could be established throughout the prospective period in the RLAI group towards monotherapy and a trend in the OA group to step out from the therapy. Similar studies [23] describe the most frequent antipsychotic combinations for the retrospective data or refer to non-antipsychotic combinations during the prospective follow-up [21]. With this respect, the current study recorded a large variety of concomitant non-antipsychotic treatments at baseline in both groups. At the 24 months prospective evaluation, RLAI recorded a reduction of co-medication by $19.3 \%$ (all $\mathrm{p} \leq 0.016$ ), which was apparently smaller than the results of the Spanish e-STAR [21]. Even in the OA group, the concomitant non-antipsychotic use tended to decrease. No statistical differences within groups could be noticed concerning this issue, whether at baseline or 24 months later. Among these classes, a concerning high proportion of benzodiazepines was observed in both study groups. The tendency to drop anticholinergics was present in both groups, with a decrease of $10 \%$ in the RLAI and $4.9 \%$ in the OA group, reductions that were more modest than described elsewhere [21] [36].

\subsection{Safety}

The treatment emergent reported adverse events were generally in consonance with studies focused on safety 
issues of RLAI [18] [37]-[39], outlining insomnia, psychotic exacerbations; SAEs such as psychomotor hyperactivity, depression, suicidal ideation were encountered in 12\% of RLAI patients, followed by hospitalization. Interesting enough, certain studies [37]-[39] insist on the incidence and quantification of extrapyramidal signs and weight gain, which the current study did not.

\subsection{Limitations}

The 24 months retrospective collection of data rendered it difficult to accurately depict treatments and admittances, due partly to limited access to other hospitals' chart-reviews. The assignment to a certain treatment arm has been done by clinical judgment and not by randomization; therefore a selection bias could not be ruled out. As for the prospective period, the report of side effects displayed heterogeneity.

\subsection{Conclusion}

The results of this e-STAR Romanian sub-study indicated that subjects suffering from schizophrenia or schizoaffective disorder who were initiated on RLAI were less likely to be hospitalized within the first 24 months after their start of treatment. Moreover, the data showed that subjects treated with RLAI experienced significant improvements in their illness severity and functioning. Discontinuation rates for RLAI were low and doses were stable throughout the 24 months following start of treatment. The need for additional antipsychotic medication or psychotropic or somatic concomitant medication was reduced. Incidences of AEs reported during the use of RLAI in a naturalistic setting compare well with those described in clinical studies with RLAI conducted in the framework of drug development.

\section{Acknowledgements}

The authors express their gratitude to the site principal investigators and monitors. In addition, we thank Dr. Mirella Marinescu who initiated this project. We thank Julie Tobback who provided medical writing services on behalf of Janssen, a division of Johnson \& Johnson Romania.

\section{Competing Interests}

Prof Dr. Micluţia received honoraria as coordinating and principal investigator in the PASTEL and e-STAR study from Johnson \& Johnson. She is a consultant or member in advisory boards for Astra-Zeneca, BMS, Eli-Lilly, and Lundbeck and a speaker for Angelini, Astra-Zeneca, BMS, Eli-Lilly, Ever, Glenmark, Lundbeck, Novartis, Pfizer, Sanofi, Servier, Terapia, and Torrent.

Dr. Vrabie has been involved in several clinical studies as an investigator or rater, carried out at the Psychiatric Hospital "Al. Obregia” in Bucharest, Romania.

Dr. Ciungu is a full time employee of Janssen, a division of Johnson \& Johnson Romania.

\section{References}

[1] Kraepelin, E. (1971) Dementia Praecox and Paraphrenia. Robert E. Krieger Publishing Co., LoCo, Huntington, New York.

[2] Watt, D.C., Katz, K. and Shepherd, M. (1983) The Natural History of Schizophrenia: A 5-Year Prospective Follow-Up of a Representative Sample of Schizophrenics by Means of a Standardized Clinical and Social Assessment. Psychological Medicine, 13, 663-670. http://dx.doi.org/10.1017/S0033291700048091

[3] Davis, J.M., Watanabe, M.D., Blake, L. and Metalon, L. (1994) Depot Antipsychotic Drugs. Place in Therapy. Drugs, 47, 741-773. http://dx.doi.org/10.2165/00003495-199447050-00004

[4] Walker, E., Kestler, L., Bollini, A. and Hochman, K.M. (2004) Schizophrenia: Etiology and Course. Annual Review of Psychology, 55, 401-430. http://dx.doi.org/10.1146/annurev.psych.55.090902.141950

[5] Hopper, K., Harrison, G., Janca, A., Bollini, A. and Sartorius, N. (2007) Recovery from Schizophrenia: An International Perspective: A Report from the WHO Collaborative Project, the International Study of Schizophrenia. Oxford University Press, Oxford.

[6] Rabinowitz, J., Levine, S.Z., Haim, R. and Hafner, H. (2007) The Course of Schizophrenia: Progressive Deterioration, Amelioration or Both? Schizophrenia Research, 91, 254-258. http://dx.doi.org/10.1016/j.schres.2006.12.013

[7] Olesen, A.V. and Mortensen, P.B. (2002) Readmission Risk in Schizophrenia: Selection Explains Previous Findings of 
a Progressive Course of Disorder. Psychological Medicine, 32, 1301-1307. http://dx.doi.org/10.1017/S0033291702005548

[8] Tandon, R., Keshavan, M.S. and Nasrallah, H.A. (2008) Schizophrenia, “Just the Facts” What We Know in 2008.2. Epidemiology and Etiology. Schizophrenia Research, 102, 1-18. http://dx.doi.org/10.1016/j.schres.2008.04.011

[9] Levine, S.Z., Lurie, I., Kohn, R. and Levav, I. (2011) Trajectories of the Course of Schizophrenia: From Progressive Deterioration to Amelioration over Three Decades. Schizophrenia Research, 126, 184-191. http://dx.doi.org/10.1016/j.schres.2010.10.026

[10] Jones, P., Rodgers, B., Murray, R. and Marmot, M. (1994) Child Development Risk Factors for Adult Schizophrenia in the British 1946 Birth Cohort. The Lancet, 344, 1398-1402. http://dx.doi.org/10.1016/S0140-6736(94)90569-X

[11] Weiser, M., Werbeloff, N., Dohrenwend, B.P., Levav, I., Yoffe, R. and Davidson, M. (2012) Do Psychiatric Registries Include All Persons with Schizophrenia in the General Population? A Population-Based Longitudinal Study. Schizophrenia Research, 135, 187-191. http://dx.doi.org/10.1016/j.schres.2011.12.023

[12] Buizer-Voskamp, J.E., Laan, W., Staal, W.G., Hennekam, E.A., Aukes, M.F., Termorshuizen, F., Kahn, R.S., Boks, M.P. and Ophoff, R.A. (2011) Paternal Age and Psychiatric Disorders: Findings from a Dutch Population Registry. Schizophrenia Research, 129, 128-132. http://dx.doi.org/10.1016/j.schres.2011.03.021

[13] Jorgensen, L., Ahlbom, A., Allebeck, P. and Dalman, C. (2010) The Stockholm Non-Affective Psychoses Study (Snaps): The Importance of Including Out-Patient Data in Incidence Studies. Acta Psychiatrica Scandinavica, 121, 389-392. http://dx.doi.org/10.1111/j.1600-0447.2009.01500.x

[14] Geddes, J.R. and Kendell, R.E. (1995) Schizophrenic Subjects with No History of Admission to Hospital. Psychological Medicine, 25, 859-868. http://dx.doi.org/10.1017/S003329170003511X

[15] Patel, M.X. and David, A.S. (2007) Medication Adherence: Predictive Factors and Enhancement Strategies. Psychiatry, 6, 357-361. http://dx.doi.org/10.1016/j.mppsy.2007.06.003

[16] Correll, C.U. (2013) Addressing Barriers to Using Long-Acting Injectable Antipsychotics and Appropriately Monitoring Antipsychotic Adverse Events. Journal of Clinical Psychiatry, 74, e16. http://dx.doi.org/10.4088/JCP.12117tx3c

[17] Velligan, D.I., Weiden, P.J., Sajatovic, M., Scott, J., Carpenter, D., Ross, R. and Docherty, J.P. (2009) The Expert Consensus Guideline Series: Adherence Problems in Patients with Serious and Persistent Mental Illness. Journal of Clinical Psychiatry, 70, 1-48. http://dx.doi.org/10.4088/JCP.7090su1cj

[18] Möller, H.J. (2005) Antipsychotic Agents. Gradually Improving Treatment from the Traditional Oral Neuroleptics to the First Atypical Depot. European Psychiatry, 20, 379-385. http://dx.doi.org/10.1016/j.eurpsy.2005.03.006

[19] Kane, J.M. (2007) Treatment Adherence and Long-Term Outcomes. CNS Spectrums, 12, 21-26.

[20] Acosta, F.J., Ramallo-Farina, Y. and Siris, S.G. (2014) Should Full Adherence Be a Necessary Goal in Schizophrenia? Full versus Non-Full Adherence to Antipsychotic Treatment. Comprehensive Psychiatry, 55, 33-39. http://dx.doi.org/10.1016/j.comppsych.2013.09.005

[21] Olivares, J.M., Rodriguez-Morales, A., Diels, J., Povey, M., Jacobs, A., Zhao, Z., Lam, A., Villalobos Vega, J.C., Cuellar, J.A., de Castro, F.J., et al. (2009) Long-Term Outcomes in Patients with Schizophrenia Treated with Risperidone Long-Acting Injection or Oral Antipsychotics in Spain: Results from the Electronic Schizophrenia Treatment Adherence Registry (e-STAR). European Psychiatry, 24, 287-296. http://dx.doi.org/10.1016/j.eurpsy.2008.12.002

[22] Rosillon, D., Caleo, S., Farmer, D., Ingham, M. and Jacobs, A. (2005) The Electronic Schizophrenia Treatment Adherence Registry—e-STAR: Baseline Results for Germany, Spain and Australia (Abstract). Value in Health, 8, 403. http://dx.doi.org/10.1016/S1098-3015(10)63094-X

[23] Naber, D., Mehnert, A., Rosillon, D., Farmer, D., Schreiner, A. and Jacobs, A. (2005) The Electronic Schizophrenia Treatment Adherence Registry-e-STAR: Baseline Results for Germany (Abstract). Value in Health, 8, 402-403. http://dx.doi.org/10.1016/S1098-3015(10)63093-8

[24] Peuskens, J., Povey, M., Van der Veken, J., Jacobs, A. and Lam, A. (2006) Patient and Physician Satisfaction with Risperidone Long-Acting Injection: 18-Month Interim Results from the Electronic Schizophrenia Treatment Adherence Registry in Belgium (Abstract). European Psychiatry, 23, S163. http://dx.doi.org/10.1016/j.eurpsy.2008.01.945

[25] Miclutia, I., Junjan, V. and Popescu, C. (2004) Stigma socialã pi impactul ei asupra încadrãrii în muncã a bolnavilor cu afecpiuni psihice. Transylvanian Review of Administrative Sciences, 3, 121-127.

[26] Karagianis, J., Novick, D., Pecenak, J., Haro, J.M., Dossenbach, M., Treuer, T., Montgomery, W., Walton, R. and Lowry, A.J. (2009) Worldwide-Schizophrenia Outpatient Health Outcomes (W-SOHO): Baseline Characteristics of Pan-Regional Observational Data from More than 17,000 Patients. International Journal of Clinical Practice, 63, 1578-1588. http://dx.doi.org/10.1111/j.1742-1241.2009.02191.x

[27] Levine, S.Z., Rabinowitz, J., Faries, D., Lawson, A.H. and Ascher-Svanum, H. (2012) Treatment Response Trajectories and Antipsychotic Medications: Examination of Up to 18 Months of Treatment in the CATIE Chronic Schizophrenia Trial. Schizophrenia Research, 137, 141-146. http://dx.doi.org/10.1016/j.schres.2012.01.014 
[28] Jager, M., Weiser, P., Becker, T., Frasch, K., Langle, G., Croissant, D., Steinert, T., Jaeger, S. and Kilian, R. (2014) Identification of Psychopathological Course Trajectories in Schizophrenia. Psychiatry Research, 215, 274-279. http://dx.doi.org/10.1016/j.psychres.2013.11.031

[29] Tandon, R., Nasrallah, H.A. and Keshavan, M.S. (2009) Schizophrenia, “Just the Facts” 4. Clinical Features and Conceptualization. Schizophrenia Research, 110, 1-23. http://dx.doi.org/10.1016/j.schres.2009.03.005

[30] Peuskens, J. and Gorwood, P. (2012) How Are We Assessing Functioning in Schizophrenia? A Need for a Consensus Approach. European Psychiatry, 27, 391-395. http://dx.doi.org/10.1016/j.eurpsy.2011.02.013

[31] Olivares, J.M., Emmerson, B., Peuskens, J., Diels, J.K., Caleo, S., Povey, M. and Lam, A. (2007) 12-Month Treatment Discontinuation Rates in Patients with Shizophrenia Treated with Risperidone Long Acting Injection (RLAI): Interim Results from the Electronic Schizophrenia Treatment Adherence Registry Project Conducted in Spain, Australia and Belgium (Abstract). Value in Health, 10, A83. http://dx.doi.org/10.1016/S1098-3015(10)68791-8

[32] Fleischhacker, W.W. (2009) Second-Generation Antipsychotic Long-Acting Injections: Systematic Review. British Journal of Psychiatry, 195, S29-S36. http://dx.doi.org/10.1192/bjp.195.52.s29

[33] Leucht, C., Heres, S., Kane, J.M., Kissling, W., Davis, J.M. and Leucht, S. (2011) Oral versus Depot Antipsychotic Drugs for Schizophrenia-A Critical Systematic Review and Meta-Analysis of Randomised Long-Term Trials. Schizophrenia Research, 127, 83-92. http://dx.doi.org/10.1016/j.schres.2010.11.020

[34] Haddad, P.M., Tiihonen, J., Haukka, J., Taylor, M., Patel, M.X. and Korhonen, P. (2001) The Place of Observational Studies in Assessing the Effectiveness of Depot Antipsychotics. Schizophrenia Research, 131, 260-261. http://dx.doi.org/10.1016/j.schres.2011.05.022

[35] Leucht, S., Tardy, M., Komossa, K., Heres, S., Kissling, W., Salanti, G. and Davis, J.M. (2012) Antipsychotic Drugs versus Placebo for Relapse Prevention in Schizophrenia: A Systematic Review and Meta-Analysis. Lancet, 379, $2063-2071$. http://dx.doi.org/10.1016/S0140-6736(12)60239-6

[36] Peuskens, J., Olivares, J.M., Hustig, H., Povey, M. and Jacobs, A. (2007) Reduced Polypharmacy in Patients Enrolled in the Electronic Schizophrnia Adherence Registry (eSTAR) and Treated with Risperidone Long-Acting Injection (RLAI) for 6 Months (Abstract). European Psychiatry, 22, S101-S220.

[37] Lindenmayer, J.P., Khan, A., Eerdekens, M., Van Hove, I. and Kushner, S. (2007) Long-Term Safety and Tolerability of Long-Acting Injectable Risperidone in Patients with Schizophrenia or Schizoaffective Disorder. European Neuropsychopharmacology, 17, 138-144. http://dx.doi.org/10.1016/j.euroneuro.2006.08.004

[38] Möller, H.J. (2006) Long-Acting Risperidone: Focus on Safety. Clinical Therapeutics, 28, 633-651. http://dx.doi.org/10.1016/j.clinthera.2006.05.014

[39] Vincent, D. (2006) Synthèse à partir de cinq études sur l’efficacité et la tolérance de la rispéridone à action prolongée. Annales Médico-Psychologiques, Revue Psychiatrique, 164, 634-641. http://dx.doi.org/10.1016/j.amp.2006.07.003 